\title{
Within a large healthcare system, the incidence of positive COVID-19 results and mortality are lower in patients on chronic hydroxychloroquine therapy
}

\author{
Soma Sen ${ }^{1} \cdot$ Ann Werner ${ }^{2} \cdot$ Aditya Shekhar ${ }^{3,4}$
}

Published online: 20 May 2020

(c) Springer Nature Switzerland AG 2020

In addition to causing significant mortality and adverse changes to the quality of life of billions globally, the COVID-19 pandemic has significantly burdened healthcare systems and will continue doing so unless more-effective means of management and treatment are identified [1]. Projections estimate that, without improved treatment methods, COVID-19 could cause 100,000-240,000 deaths in the USA [1]. In vitro and in vivo studies have identified the antimalarial medicine hydroxychloroquine as a potential pharmacological treatment option [2-4]. Currently, hydroxychloroquine is a well-established medication prescribed to treat systemic lupus erythematosus (SLE) and rheumatoid arthritis (RA) [4].

To understand the incidence of patients with existing hydroxychloroquine prescriptions for either SLE or RA testing positive for COVID-19, data from a large healthcare system were examined.

Between 1 April 2019 and 31 March 2020, there were $1,271,014$ unique patient encounters in the database. During this period, a total of 2945 COVID-19 tests were performed, with 125 (4.24\%) being positive. Of the tests performed, 2849 were performed in patients without a hydroxychloroquine prescription, with 124 (4.35\%) being positive; the remaining 96 tests were performed in patients with existing hydroxychloroquine prescriptions for SLE or RA, with one (1.04\%) being positive. Among the COVID19 positive patients, two $(1.61 \%)$ who were not prescribed hydroxychloroquine died, but the patient who was prescribed

Aditya Shekhar

shekh046@umn.edu

1 Park Nicollet Heart and Vascular Center, St. Louis Park, USA

2 HealthPartners Institute, Bloomington, USA

3 The University of Chicago, Chicago, USA

4 The University of Minnesota, Minneapolis, USA hydroxychloroquine did not. In terms of COVID-19 testing, $0.232 \%$ of all patients within the database system were tested, whereas $5.096 \%$ of patients with hydroxychloroquine prescriptions within the system were tested.

These results make a preliminary case for using hydroxychloroquine as a form of prophylactic treatment against COVID-19, considering the lower incidence of positive tests and no mortality among patients prescribed hydroxychloroquine. Furthermore, the fact that a greater percentage of patients with a hydroxychloroquine prescription were tested might reflect providers having higher indexes of suspicion of COVID-19 in these patients. This is interesting because our expectation is that an inherently immunocompromised population, such as one prescribed hydroxychloroquine, would be more likely to contract COVID-19. That being said, further study of hydroxychloroquine is warranted to ensure its efficacy as a means of prophylactically preventing the onset or progression of COVID-19. While these data are observational in a relatively small population and a clinical trial would be most helpful, we may lose valuable time and invaluable lives while waiting for trial results, considering the projected mortality due to COVID-19. We encourage other healthcare systems to examine their own databases to see if the trends we identified can be seen more broadly (Table 1). 
Table 1 Results of COVID-19 testing in patients prescribed/not prescribed hydroxychloroquine

\begin{tabular}{llrl}
$\begin{array}{l}\text { Patient prescribed } \\
\text { hydroxychloro- } \\
\text { quine? }\end{array}$ & $\begin{array}{l}\text { No. of } \\
\text { patients } \\
\text { tested }\end{array}$ & $\begin{array}{l}\text { No. of posi- } \\
\text { tive tests }(\%)\end{array}$ & No. of deaths (\%) \\
\hline No & 2849 & $124(4.35)$ & $2(1.61)$ \\
Yes & 96 & $1(1.04)$ & 0 \\
\hline Total & 2945 & $125(4.24)$ & $2(1.60)$
\end{tabular}

Acknowledgements Data were provided by the Health Partners Institute, a research arm of Health Partners Park Nicollet Care Group, Minneapolis, $\mathrm{MN}$.

Author contributions All authors contributed equally to the creation of this manuscript and had full access to all data.

\section{Compliance with ethical standards}

Funding None.

Conflict of interest The authors declare they have no conflict of interest.

\section{References}

1. Shear MD, Crowley M, Glanz J. Coronavirus may kill 100,000 to 240,000 in U.S. despite actions, officials say. New York: New York Times; 31 Mar 2020. https://www.nytimes.com/2020/03/31/ us/politics/coronavirus-death-toll-united-states.html. Accessed 1 Apr 2020.

2. World Health Organization. WHO Director-General's opening remarks at the media briefing on COVID-19 [media briefing 11 Mar 2020]. https://www.who.int/dg/speeches/detail/who-directorgeneral-s-opening-remarks-atthe-media-briefing-on-COVID-19. Accessed 1 Apr 2020.

3. Yao X, Ye F, Zhang M, et al. In vitro antiviral activity and projection of optimized dosing design of hydroxychloroquine for the treatment of severe acute respiratory syndrome coronavirus 2 (SARS-CoV-2). Clin Infect Dis. https://doi.org/10.1093/cid/ ciaa237 (Epub 2020 Mar 9).

4. Gautret P, Lagier JC, Parola P, et al. Hydroxychloroquine and azithromycin as a treatment of COVID-19: results of an openlabel non-randomized clinical trial. Int J Antimicrob Agents. https ://doi.org/10.1016/j.ijantimicag.2020.105949 (Epub 20 Mar 2020).

5. Colson P, Rolain JM, Lagier JC, et al. Chloroquine and hydroxychloroquine as available weapons to fight COVID-19 [editorial]. Int J Antimicrob Agents. 2020;55(4):105932. 